\title{
A New Front End Capacitive Converter Fed Switched Reluctance Motor for Torque Ripple Minimization
}

\author{
S. Muthulakshmi, R. Dhanasekaran \\ Department of Electrical and Electronics, Syed Ammal Engineering College, Ramanathapuram, India \\ Email: key3_sss@rediffmail.com,rdhanashekar@yahoo.com
}

Received 5 March 2016; accepted 26 April 2016; published 29 April 2016

Copyright (C) 2016 by authors and Scientific Research Publishing Inc.

This work is licensed under the Creative Commons Attribution International License (CC BY).

http://creativecommons.org/licenses/by/4.0/

(c) (i) Open Access

\begin{abstract}
This paper presents new converter for torque ripple minimization of three phases Switched Reluctance Motor (SRM). The proposed converter has basic passive circuit which includes two diodes and one capacitor to the front end of an asymmetric converter with a specific end goal to get a high magnetization and demagnetization voltage. In view of this boost capacitor, the charge and demagnetization voltage are higher. Accordingly, it can reduce the negative torque generation from the tail current and enhance the output power. The proposed converter circuit is equipped for minimizing the SRM torque ripple furthermore enhancing the average torque when contrasted with traditional converter circuit. A three-phase SRM is modeled and the simulation output for no load and stacked condition depicts that the proposed converter has better performance when contrasted with traditional converter. It is appropriate for electric vehicle applications. The proposed framework is simulated by utilizing MATLAB/Simulink environment and their outcomes are examined extravagantly.
\end{abstract}

\section{Keywords}

SRM, MATLAB, Torque Ripple, Asymmetric Converter, Magnetization, Demagnetization

\section{Introduction}

The switched reluctance motor incorporates straight forward and solid structure with low latency and direct drive capacity and is particularly suitable for top accuracy and fast creating mechanism. Inception of torque ripple can be found in [1]. Generally there are two methodologies for lessening torque ripple. One technique is to machine design approach, and another is to electronic control approach. 
Some researchers focused on machine outline approach by changing the primary dimension of motor. Torque sharing function was applied for reducing the torque ripple in SRM [2]. PWM based control strategies are executed in [3]. The electronic control methodology depends on control parameters like the supply voltage, turn ON, turn OFF point and reference current [4]. However in speed management with the SRM confronting a few issues inferable from its non-direct attributes, to improve the performance of motor some advanced control innovations have been actualized, similar to flux linkage and current profile control [5]. Torque ripple influences the performance of SRM particularly in the low speed range [6]. An intergrated approach of the machine and converter was developed, to enhance the torque at low speed with seven and nine phase motor [7]. Drawback of these higher phase machines increases the fringing impact among the phases.

A well-known strategy to diminish torque ripple is to utilize suitable phase current profile. A strategy for torque ripple optimizing so as to lessen the phase current profile was contemplated in [7]. A Lyapunov function based direct torque controller for torque ripple minimization in SRM drive is accounted for in [9]. Optimization method for the minimization of torque ripple in SRM was accounted for in [2] [10]. The issue of picking terminating plots for achieving most extreme proficiency in single pulse controlled SRM drive is investigated [11]. Torque ripple diminishment scheme utilizing B-Spline neural system is presented [12].

A single controllable switch four-quadrant SRM drive with the minimum component has effectively been exhibited in [13]. Two-switch based SRM drive was proposed for high volume applications [14]. The torque response of SRM can be expanded with high demagnetization voltage on changing which empowers quicker decrease of phase current to zero after aligning position [15]. SRM operation with controlled demagnetization voltage higher than the magnetization voltage is studied and the impact of high demagnetization voltage on torque response is discussed [16].

SRMs are unique in relation to other AC machines since they utilize reluctance torque in the variety locale of inductance, which requires a square-wave excitation current as opposed to the sinusoidal current that is utilized as a part of an AC machine. Keeping in mind the end goal to make a square-wave current controlled voltage is crucial at excitation and demagnetization modes. Nonetheless, the excitation and demagnetization voltages are restricted by the DC link voltage in traditional Switched Reluctance (SR) drives. Quick excitation and demagnetization are troublesome in rapid regions [17] [18]. However, the turn-on angle can be controlled to enhance the output torque; the negative torque dependably lessens the output torque that outcomes in low productivity. High demagnetization voltage is a decent decision to enhance performance. It can get a quick lessening in the tail current after the aligned position, decrease the negative torque and augment the dwell angle [19]. The buckboost converter was utilized as a part of SR converters to enhance demagnetization voltage. Be that as it may, high expenses and complicated boost voltage control strategy kept its applications. Accordingly, studies proposed two types of passive boost dc link converters: two capacitors associated in arrangement and two capacitors associated in parallel. These two converters are straightforward, and the demagnetization current charges an extra capacitor and supplies higher efficacious boost voltage than the input DC link voltage [19] [20]. The performance analysis of switched reluctance motor is done using hysteresis controller [21]. Switched Reluctance Motor (SRM) drive with four-phase winding by split converter was demonstrated [22]. The multiport converter with reduced capacitance for SRM was implemented [23]. In conventional asymmetric converter the large value of capacitance is required whereas in multiport converter with reduced capacitor causes high dc ripple voltage. Due to this, the current commutation process was accelerated.

\section{Numerical Model of SRM}

The numerical model of SRM is made out of an arrangement of electrical comparison for every phase and the mathematical statement of mechanical framework. The mathematical representation of voltage per phase is given by

$$
v=R_{s} i+\frac{\mathrm{d} \lambda(\theta, i)}{\mathrm{d} t}
$$

$R_{S}$-Resistance per phase.

$\lambda-$ Flux linkage of winding per phase.

$$
\lambda=L(\Theta, i) i
$$

where $L$ is the phase inductance relies on the rotor position and phase current. 


$$
v=R_{s} i+L(\theta, i) \frac{\mathrm{d} i}{\mathrm{~d} t}+\frac{\mathrm{d} L(\theta, i)}{\mathrm{d} \theta} i \varpi_{m}
$$

$\varpi_{m}$ —angular velocity.

The emf induced in the winding is written as

$$
e=\frac{\mathrm{d} L(\theta, i)}{\mathrm{d} \theta} i \varpi_{m}
$$

where Kb-emf constant

$$
\begin{gathered}
e=i \varpi_{m} K b \\
K_{b}=\frac{\mathrm{d} L(\theta, i)}{\mathrm{d} \theta} .
\end{gathered}
$$

The torque produced in a phase is given by

$$
T(\theta, i)=\frac{1}{2} i^{2} \frac{\mathrm{d} L(\theta, i)}{\mathrm{d} \theta} .
$$

The mechanical equation

$$
T_{t}-T_{l}=J_{m} \frac{\mathrm{d} \varpi_{m}}{\mathrm{~d} t}+B_{m} \varpi_{m}
$$

where $T_{l}$-load torque, $J_{m}$-moment of inertia, $B_{m}$-friction coefficient. In view of the above mathematical statement [1]-[7] the dynamic model of 6/4, 3 phase SRM is created by MATLAB/SIMULINK environment.

\section{Traditional Converter}

The three phase traditional converter circuit outline is appeared in Figure 1. The circuit ought to be controlled adaptable in light of the fact that every phase is free. Along with various conditions of phase switches, the phase windings can acquire three switching states that are magnetization, de magnetization and freewheeling mode.

\section{Analysis and Modes of Proposed Converter}

The circuit diagram of proposed converter is appeared in Figure 2. The circuit ought to be controlled adaptable in light of the fact that every phase is autonomous. Contrasted with the asymmetric bridge converter, it increases two diodes $D_{c d}, D$, and a boost capacitance $C_{c d}$. Notwithstanding, the higher voltages are connected to phase windings and it can acquire faster excitation current and demagnetization current. So it can enhance current following impact and productivity, lessen the torque ripple. It could likewise enhance the performance when the converter supplies an extra boosted voltage to SRM.

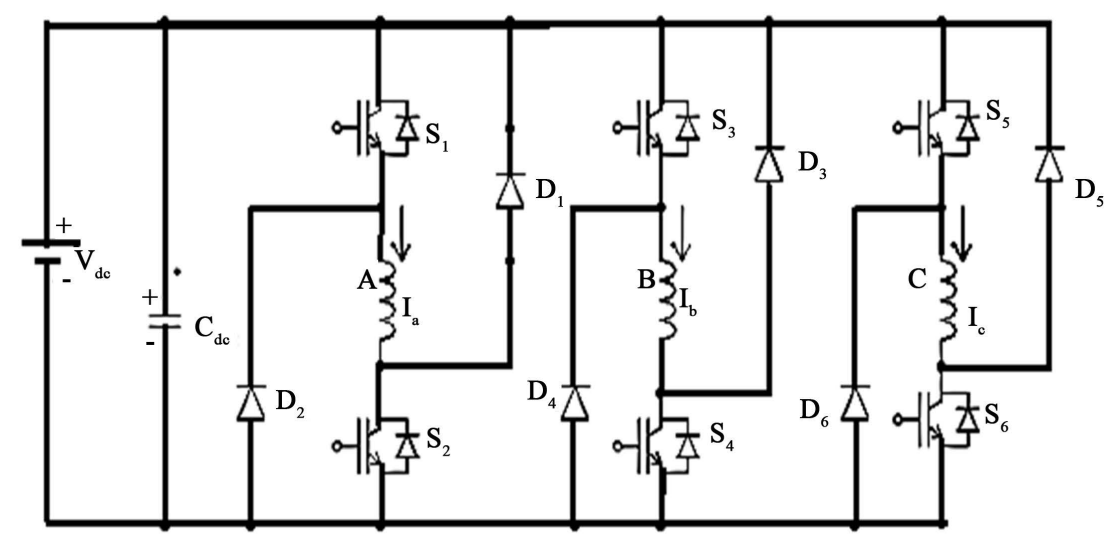

Figure 1. Traditional converter circuit. 


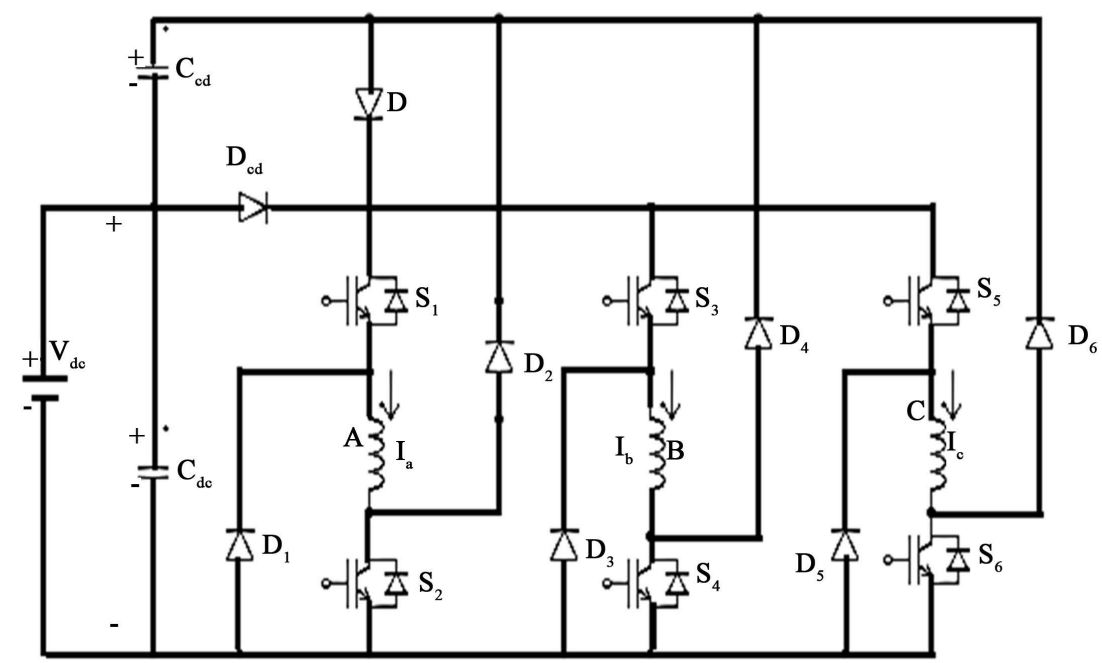

Figure 2. Proposed converter circuit.

\subsection{Mode 1 (Excitation 1)}

In the mode 1 , two phases switch $S_{1}, S_{2}$ and diode $D$ all turn $\mathrm{ON}$ and the higher voltage is applied to phase winding because the capacitor voltage $\left(V_{c d}\right)$ is added to the phase voltage. The winding is energized and the current flow path is shown in Figure 3(a). The circulation current can be obtained in Equation (8).

$$
V_{d c}-E_{a}-V_{c d}=R_{a} I_{a}+L_{l} \frac{\mathrm{d} I_{a}}{\mathrm{~d} t}
$$

\subsection{Mode 2 (Excitation 2)}

In the mode 2, phase switches $\left(S_{1}, S_{2}\right)$ turn ON and switch $D$ turn OFF. The current flow path is shown in Figure 3(b). This mode is similar to that of excitation mode in traditional converter. When capacitor $C_{d c}$ is charging the switches $\left(S_{1}, S_{2}\right)$ and diode $D_{c d}$ turn ON, the circuit equation can be written as (9) As the switches turn OFF, capacitor is being discharged ,the capacitor voltage can be written as (10)

$$
\begin{gathered}
V_{d c}-E_{a}=R_{a} I_{a}+L_{l} \frac{\mathrm{d} I_{a}}{\mathrm{~d} t} \\
\frac{\mathrm{d} V_{d c}}{\mathrm{~d} t}=-\frac{1}{C} I_{d c}=-\frac{1}{C} I_{a} .
\end{gathered}
$$

\subsection{Mode 3 (Freewheeling)}

In the state 0 , one of phase switches turn ON $S_{2}$ and the other one $S_{1}$ turn OFF and diode $D_{2}$ turn OFF at the same time. The current flow path is shown in Figure 3(c). This mode is also similar to that of freewheeling mode in traditional converter. The voltage equation of phase during one switch $S_{2}$ and one diode turn ON $D_{1}$ can be written as (11)

$$
V_{a}+I_{a} R_{a}=-V_{f} V_{d m} .
$$

\subsection{Mode 4 (Demagnetization)}

In mode 4 all phase switches and diode $D$ are turn OFF, the state is named as de-magnetization mode and higher negative voltage are applied to phase windings. The stored magnetic energy is returned to the supply when compared with asymmetric bridge converter, it can obtain faster demagnetization current when current is dropping and also obtain better performance. The current flow path is indicated in Figure 3(d). The voltage and current response are obtained during demagnetization in Equations (12) and (13). The voltage across the phase B can be written as in (14). 


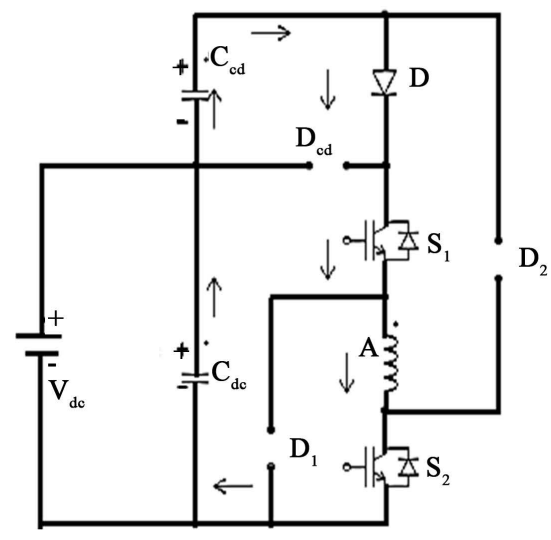

(a)

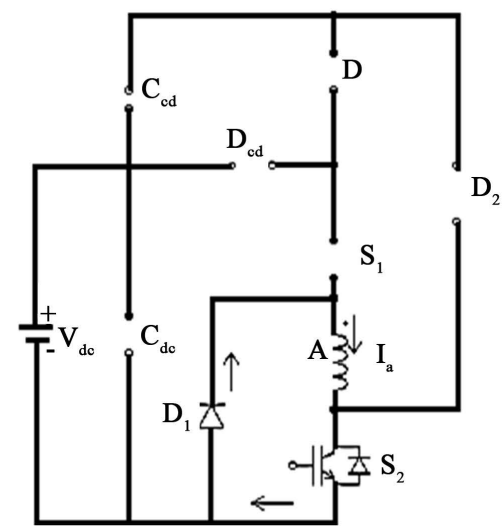

(c)

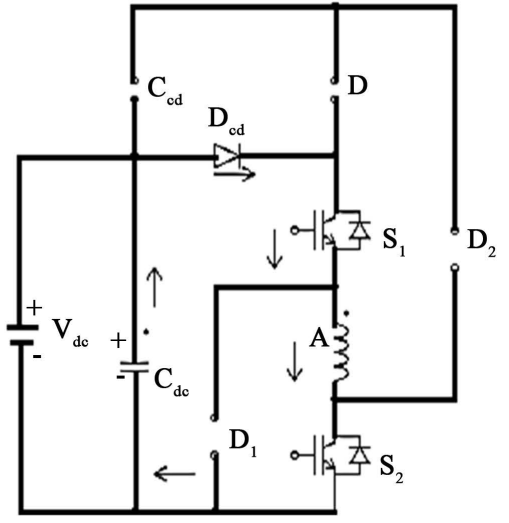

(b)

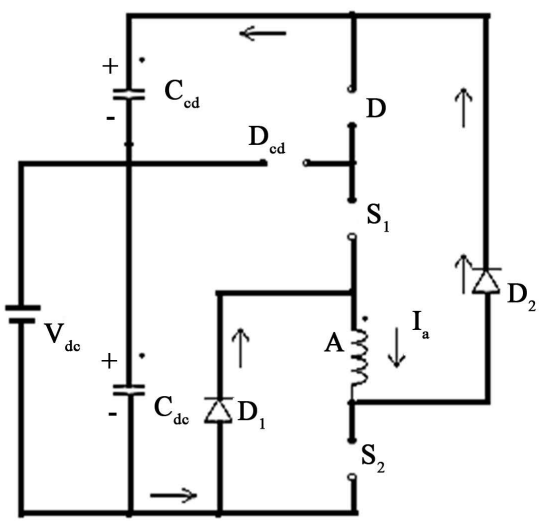

(d)

Figure 3. Modes of operation of proposed converter. (a) Excitation 1; (b) Excitation 2; (c) Freewheeling; (d) Demagnetization.

$$
\begin{gathered}
V_{d c}-V_{d}-V_{c d}=R_{a} I_{a}+L_{l} \frac{\mathrm{d} I_{a}}{\mathrm{~d} t}+E_{a} \\
\frac{\mathrm{d} V_{d c}}{\mathrm{~d} t}=-\frac{1}{C} I_{d c}=-\frac{1}{C}\left(-I_{a}+I_{b}\right)=\frac{1}{C}\left(I_{a}-I_{b}\right) \\
V_{d c}-E_{b}=R_{b} I_{b}+L_{l} \frac{\mathrm{d} I_{b}}{\mathrm{~d} t}
\end{gathered}
$$

From Equation (13) the value of boost capacitor is designed. The boost capacitor value must be less than the dc link capacitor. The value of boost capacitor is designed as $47 \mu \mathrm{F}$.

\section{Torque Ripple Minimization}

Since the saliency of the stator and rotor, the torque ripple is generated when the previous phase is being energized opposite voltage and the later phase has been energized. The purpose of crossing point between the two energized phases must be progressed to a higher quality for minimizing the torque ripple. Equation suggests (15), positive torque is created when the machine inductance is rising because the shaft angle is increasing $d L / d \Theta$ is positive. Equally, a negative torque is generated by supplying the SRM winding with current while $d L / d \Theta$ is negative. Henceforth by controlling the current and selecting the suitable turn ON and turn OFF angle will prompt minimize torque ripple in SRM drive.

The expression for the torque ripple is given in (15)

$$
T R=\left(T_{\max }-T_{\min }\right) / T_{\text {mean }}
$$


where $T_{\max }-$ Maximum estimation of torque $(\mathrm{N} \cdot \mathrm{m})$.

$T_{\min }$-Minimum estimation of torque $(\mathrm{N} \cdot \mathrm{m})$.

$T_{\text {mean }}-$ Mean estimation of torque $(\mathrm{N} \cdot \mathrm{m})$.

So as to minimize the torque ripple positive torque must be upgraded and negative torque generation must be entirely stayed away from.

\section{Results and Discussions}

To validate the performance of switched reluctance motor, the proposed converter was simulated by MATLAB/ simulink under load $T_{L}=2.5 \mathrm{~N} \cdot \mathrm{m}$ is appeared in Figure 4 respectively Figure 5. depicts the simulation outline for proposed converter. The DC supply voltage of $240 \mathrm{~V}$ is used. The converter turn-on and turn-off angles are kept constant at 45 degree and 75 degree, respectively, over the speed range. The reference current is $100 \mathrm{~A}$ and

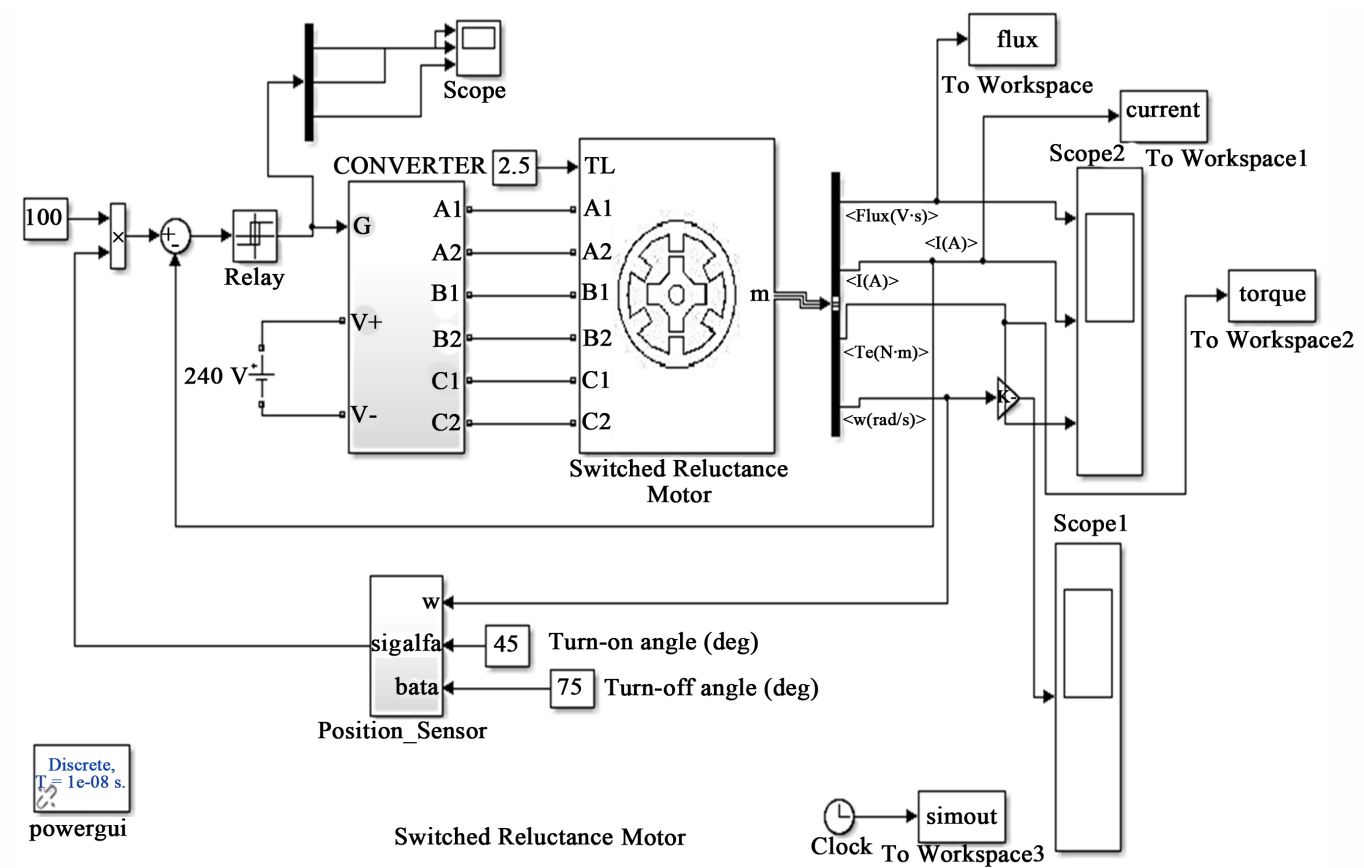

Figure 4. Simulation diagram for three phases SRM.

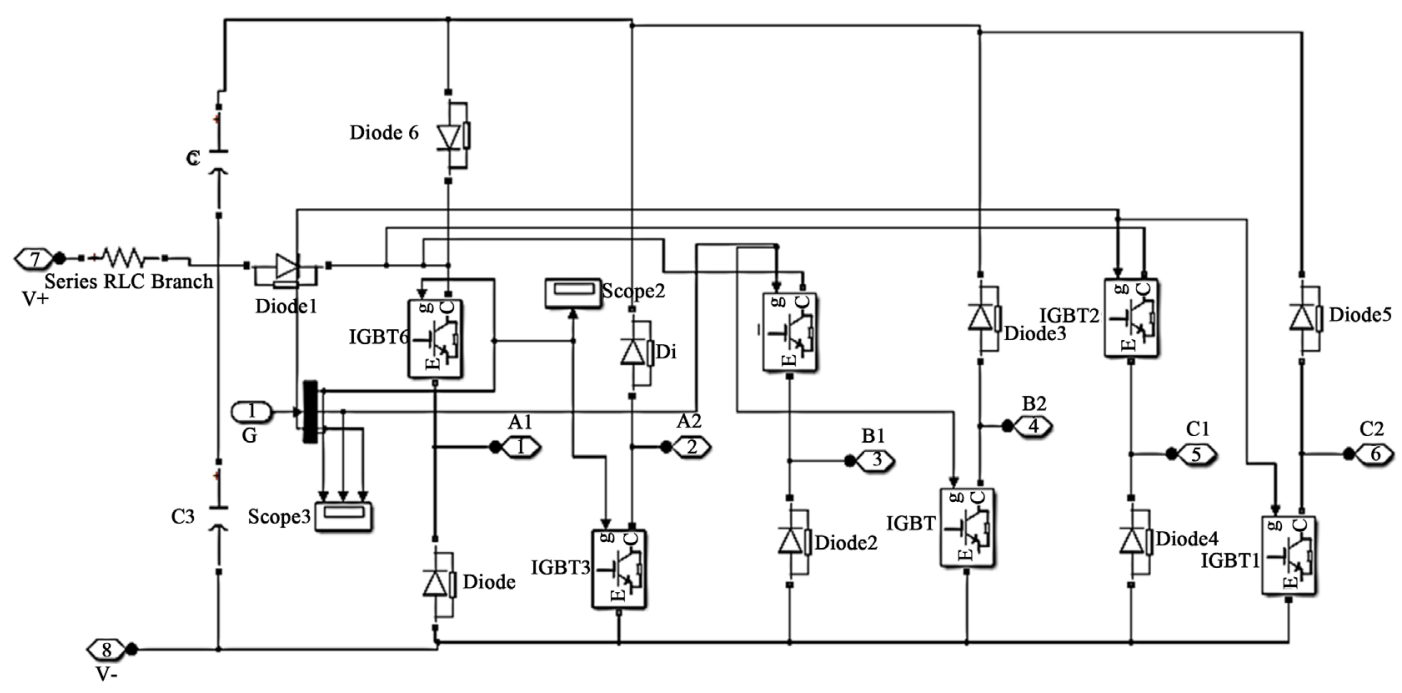

Figure 5. Simulation diagram for proposed circuit. 
the hysteresis band is chosen as $\pm 10 \mathrm{~A}$. The SRM is started by applying the step reference to the regulator input. The acceleration rate depends on the load characteristics. To shorten the starting time, a very light load was chosen. Since only the currents are controlled, the motor speed will increase according to the mechanical dynamics of the system. In current controlled mode, the average value of the developed torque is approximately proportional to the current reference. In addition to the torque ripple due to phase transitions, we note also the torque ripple created by the switching of the hysteresis regulator.

Comparative examination of the ordinary and proposed converter response are appeared in Figures 6-11 respectively. Figure 6 depicts the consequences of traditional converter at no load condition with turn ON angle

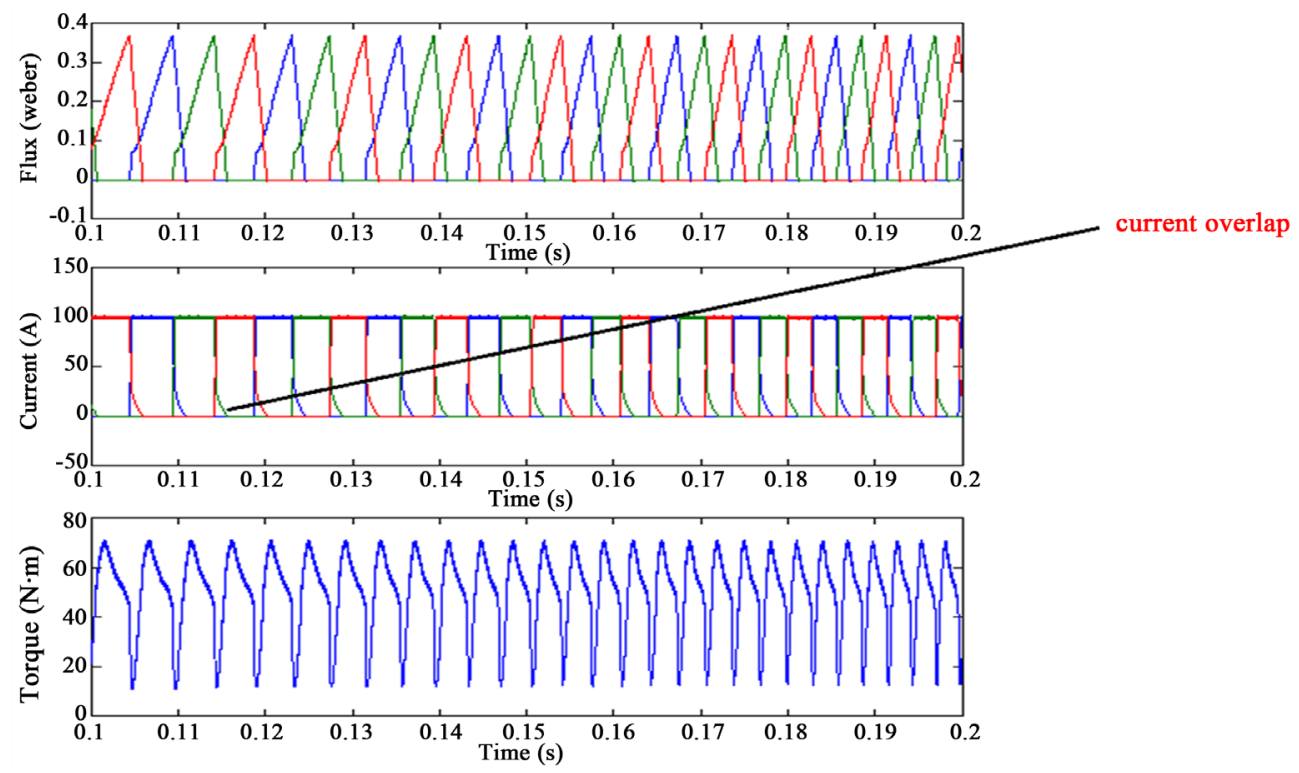

Figure 6. Traditional converter with $\Theta_{\mathrm{ON}}=45^{\circ}, \Theta_{\mathrm{OFF}}=75^{\circ}, T_{L}=0 \mathrm{NM}$.
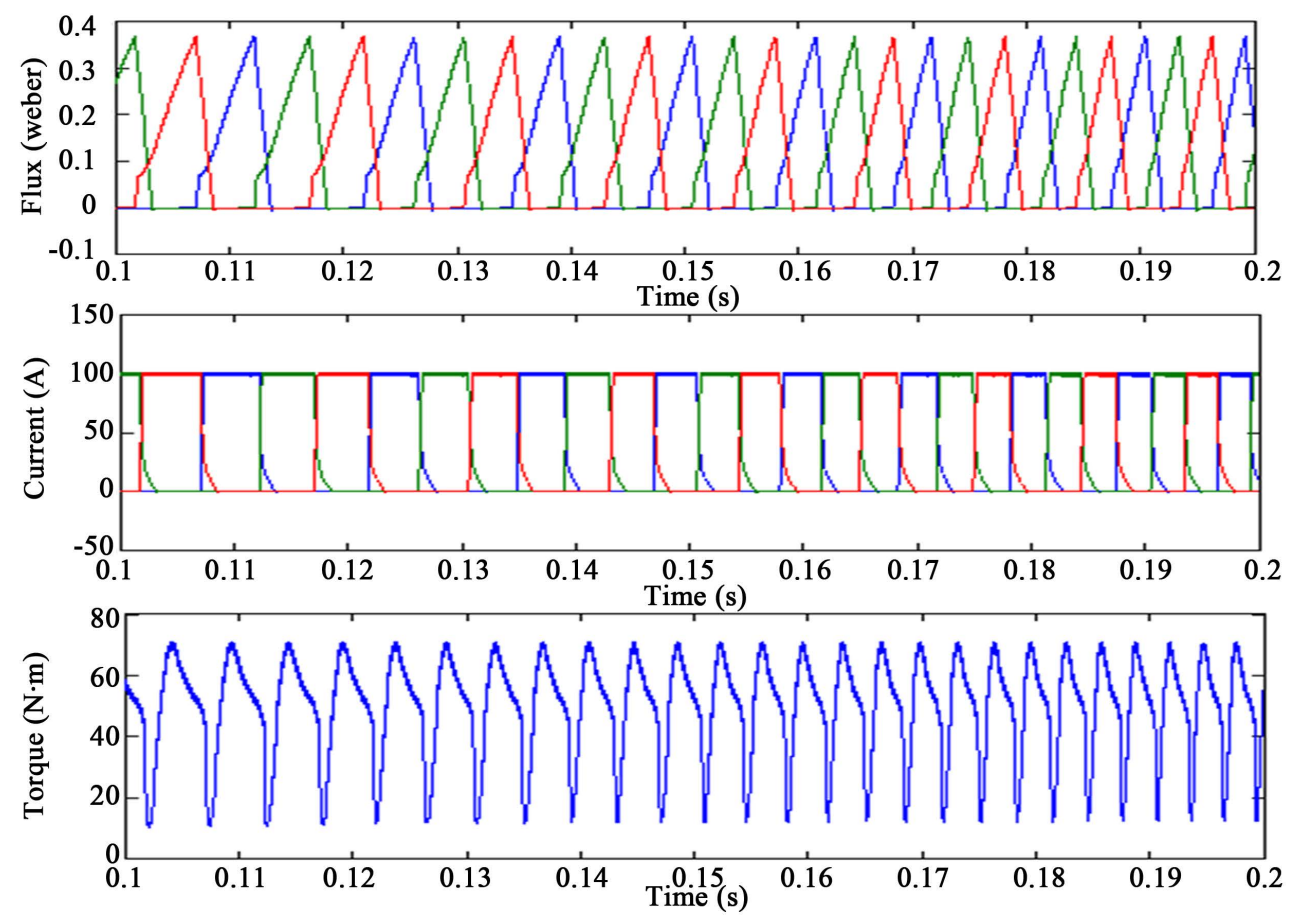

Figure 7. Traditional converter with $\Theta_{\mathrm{ON}}=45^{\circ}, \Theta_{\mathrm{OFF}}=75^{\circ}, T_{L}=2.5 \mathrm{NM}$. 

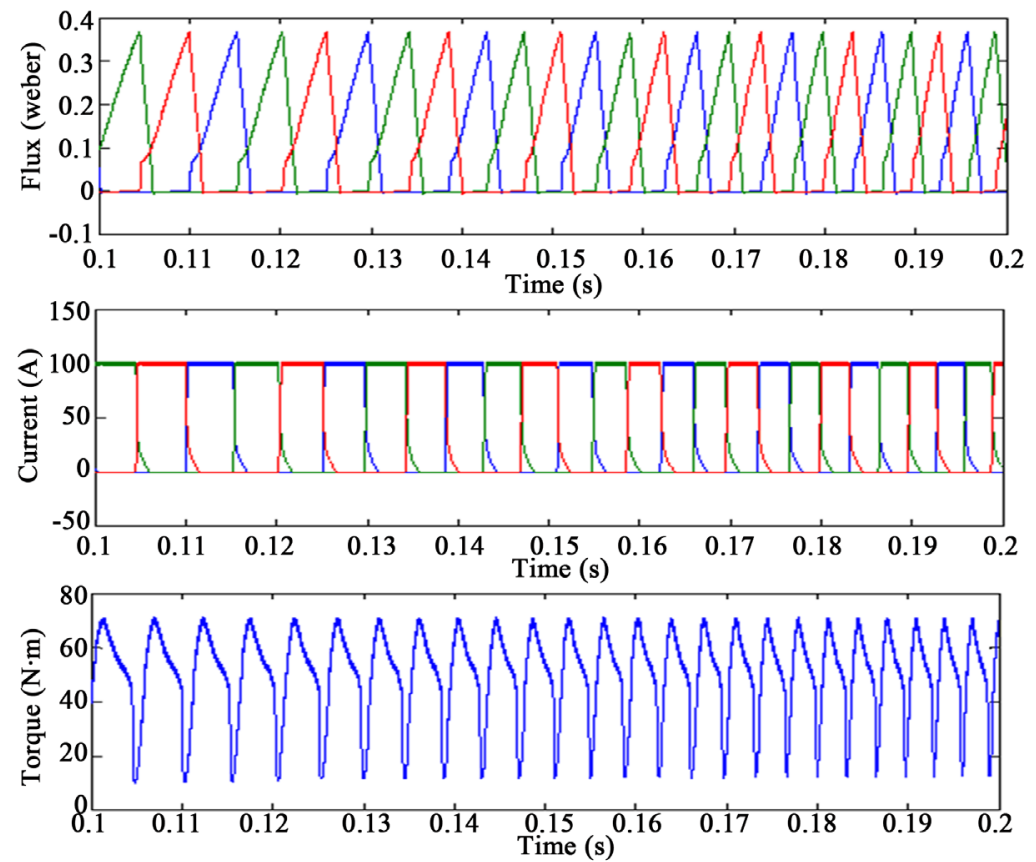

Figure 8. Traditional converter with $\Theta_{\mathrm{ON}}=45^{\circ}, \Theta_{\mathrm{OFF}}=75^{\circ}, T_{L}=5 \mathrm{~N} \cdot \mathrm{m}$.
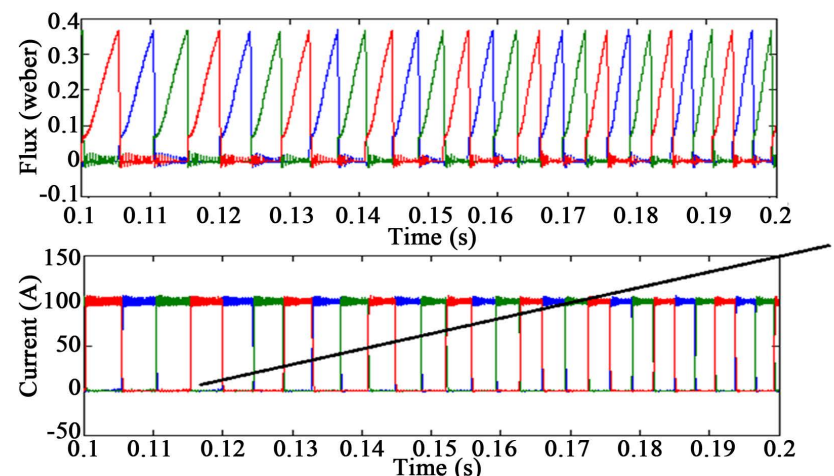
current overlap get reduced

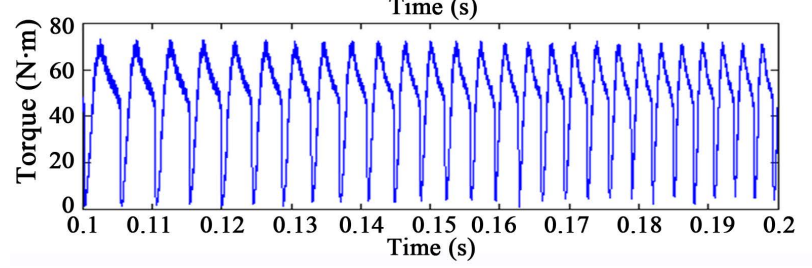

Figure 9. Proposed converter with $\Theta_{\mathrm{ON}}=45^{\circ}, \Theta_{\mathrm{OFF}}=75^{\circ}, T_{L}=0 \mathrm{~N} \cdot \mathrm{m}$.

45 degree and turn OFF angle 75 degree. It can be seen in Figure 6, the current overlap occurred between two successive phases. From the torque waveform we observe that the change in torque is $58 \mathrm{~N} \cdot \mathrm{m}$ and the mean torque is $21.66 \mathrm{~N} \cdot \mathrm{m}$ and the torque ripple is computed from the above data and torque ripple rate acquired as 2.688. Figure 7 depicts the consequences of traditional converter at $T_{L}=2.5 \mathrm{~N} \cdot \mathrm{m}$. From the torque waveform we observe that change in torque is $57 \mathrm{~N} \cdot \mathrm{m}$ and the average torque is $23.89 \mathrm{~N} \cdot \mathrm{m}$ and the torque ripple is ascertained from the above data and torque ripple rate got as 2.396. Figure 8 depicts the consequences of traditional converter at $T_{L}=5 \mathrm{~N} \cdot \mathrm{m}$. From the torque waveform we observe that change in torque is $58 \mathrm{~N} \cdot \mathrm{m}$ and the average torque is $26.79 \mathrm{~N} \cdot \mathrm{m}$ and the torque ripple is ascertained from the above data and torque ripple rate acquired as 2.165. In proposed converter ,the presence of boost capacitor causes high demagnetisation voltage and also the fall time current get reduced to zero before the next phase is energised. 

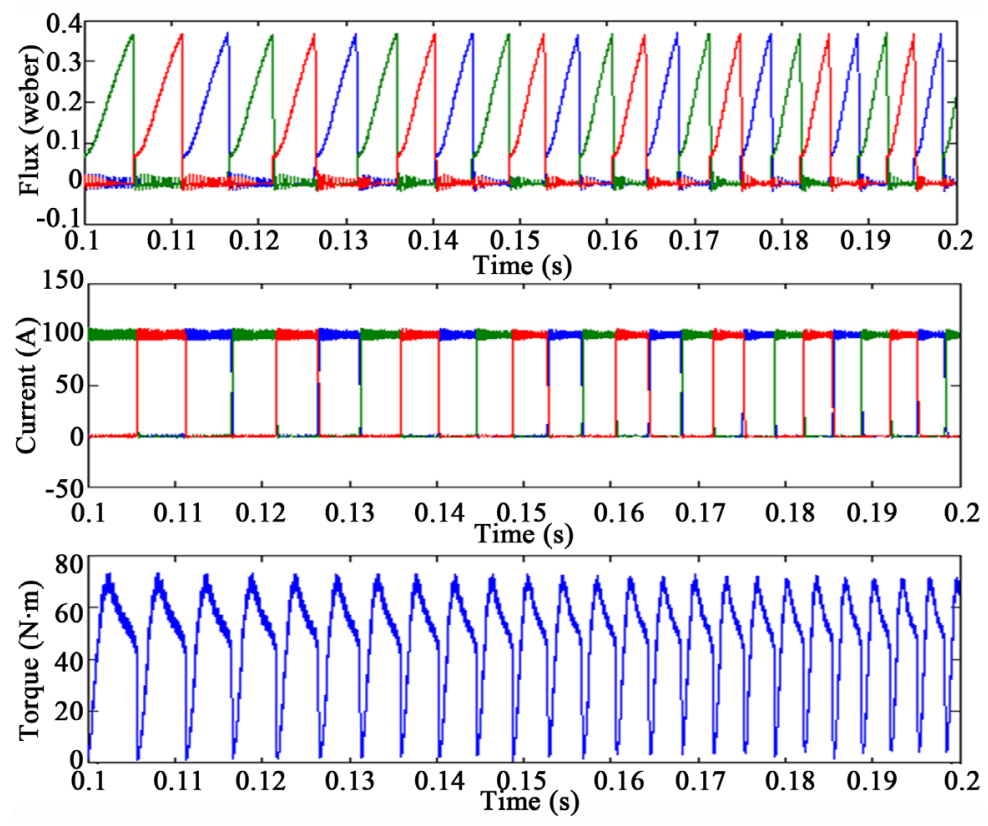

Figure 10. Proposed converter with $\Theta_{\mathrm{ON}}=45^{\circ}, \Theta_{\mathrm{OFF}}=75^{\circ}, T_{L}=2.5 \mathrm{~N} \cdot \mathrm{m}$.
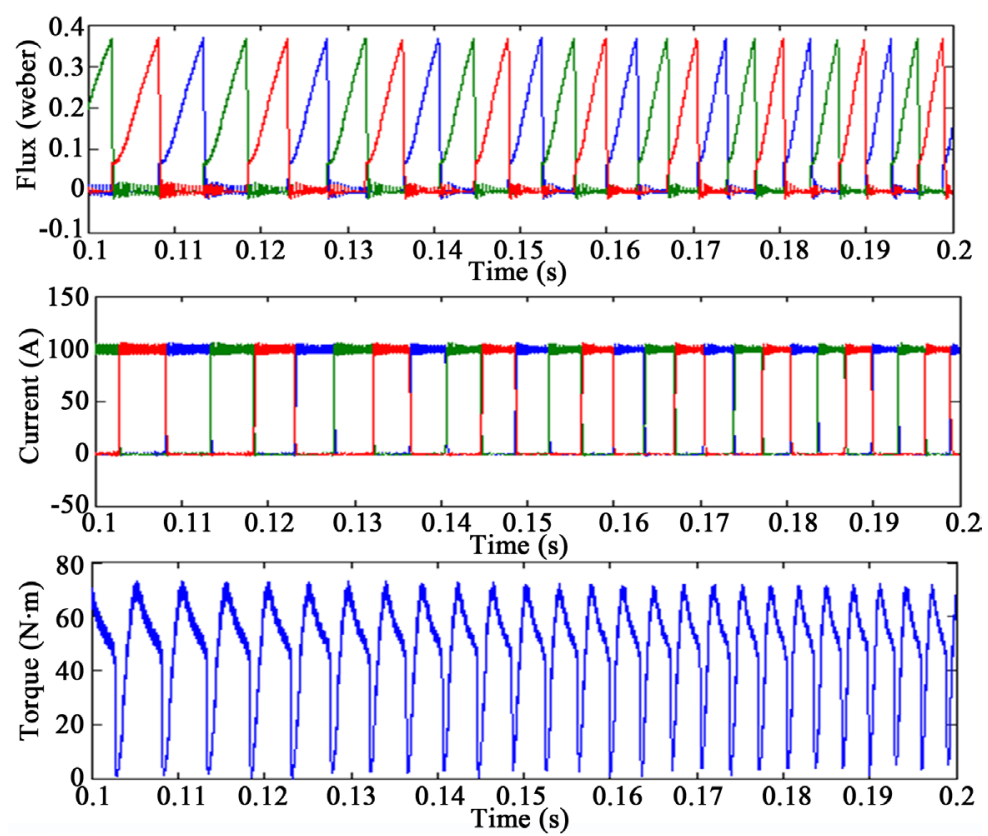

Figure 11. Proposed converter with $\Theta_{\mathrm{ON}}=45^{\circ}, \Theta_{\mathrm{OFF}}=75^{\circ}, T_{L}=5 \mathrm{~N} \cdot \mathrm{m}$.

Figure 9 depicts the results of proposed converter at no load condition with turn ON angle 45 degree and turn OFF angle 75 degree. It can be seen in Figure 9, the current ovrlap get reduced. From the torque waveform we observe that change in torque is $66 \mathrm{~N} \cdot \mathrm{m}$ and the average torque is $32.09 \mathrm{~N} \cdot \mathrm{m}$ and the torque ripple is ascertained from the above data and torque ripple rate acquired as 2.056. Figure 10 shows the results of proposed converter at $T_{L}=2.5 \mathrm{~N} \cdot \mathrm{m}$. From the torque waveform we observe that change in torque is $70 \mathrm{~N} \cdot \mathrm{m}$ and the average torque is $35.19 \mathrm{~N} \cdot \mathrm{m}$ and the torque ripple is computed from the above data and torque ripplerate acquired as 1.932 . Figure 11 depicts the results of proposed converter at $T_{L}=5 \mathrm{~N} \cdot \mathrm{m}$. From the torque waveform we observe that change in torque is $70 \mathrm{~N} \cdot \mathrm{m}$ and the average torque is $38.22 \mathrm{~N} \cdot \mathrm{m}$ and the torque ripple is computed from the above data and torque ripple rate got as 1.831 . Table 1 depicts the comparison of traditional and proposed 
Table 1. Comparison of traditional converter with proposed converter (switching angle $\Theta_{\mathrm{ON}}=45^{\circ}, \Theta_{\mathrm{OFF}}=75^{\circ}$ ).

\begin{tabular}{ccccc} 
& A & B & C & D \\
\hline $\begin{array}{c}\text { Traditional } \\
\text { converter }\end{array}$ & 0 & 58 & 21.66 & $\mathbf{2 . 6 8 8}$ \\
& 2.5 & 57 & 23.89 & $\mathbf{2 . 3 9 6}$ \\
\hline $\begin{array}{c}\text { Proposed } \\
\text { converter }\end{array}$ & 5 & 58 & 26.79 & $\mathbf{2 . 1 6 5}$ \\
\hline
\end{tabular}

A-load torque, $\mathrm{B}$ - change in torque, $\mathrm{C}$ - average torque, $\mathrm{D}$ - torque ripple.

converter at different switching angle. In proposed converter the current tracing effect is greater than ordinary converter. Henceforth dynamic performance is improved.

\section{Conclusion}

In this paper, a new front end capacitive switched reluctance motor drive has been introduced. This topology includes one boost capacitor and two diodes in addition to the traditional converter. The boost capacitor gives high magnetization and demagnetization voltage to the motor winding. The torque ripple is quite excessive and the current tracing effect is not very good for asymmetric converter. The proposed converter obtains faster excitation current during magnetization and quick demagnetization current for the duration of demagnetization period. So it will possibly also support current tracing effect, average torque, and reduce the torque ripple. It is well suited to electrical vehicle, electric traction and aerospace utility.

\section{References}

[1] Husain, I. (2002) Minimization of Torque Ripple in SRM Drives. IEEE Transactions on Industrial Electronics, 49, 28-39. http://dx.doi.org/10.1109/41.982245

[2] Xue, X.D., Cheng, K.W.E. and Ho, S.L. (2009) Optimization and Evaluation of Torque Sharing Functions for Torque Ripple Minimization in Switched Reluctance Motor Drives. IEEE Transaction on Power Electronics, 24, $2076-2090$. http://dx.doi.org/10.1109/TPEL.2009.2019581

[3] Husain, I. and Ehsani, M. (1996) Torque Ripple Minimization in Switched Reluctance Motor Drives by PWM Current Control. IEEE Transaction on Power Electronics, 11, 83-88. http://dx.doi.org/10.1109/63.484420

[4] Krishnan, R. (2001) Switched Reluctance Motor Drives. CRC Press, Boca Raton. http://dx.doi.org/10.1201/9781420041644

[5] Cheok, A.D. and Fukuda, Y. (2002) A New Torque and Flux Control Method for Switched Reluctance Motor Drives. IEEE Transaction on Power Electronics, 17, 543-557. http://dx.doi.org/10.1109/TPEL.2002.800968

[6] Russak, H.I. and Elbulukt, M. (1998) Torque Ripple Minimization in Switched Reluctance Machines over a Wide Speed Range. IEEE Transactions on Industrial Electronics, 34, 1105-1112.

[7] Pollock, C. and Williams, B.W. (1987) An Integrated Approach to Switched Reluctance Motor Design. Proceedings of EPE, 885-870.

[8] Mir, S., Elbulukt, M. and Husain, I. (1999) Torque Ripple Minimization in Switched Reluctance Motor Using Adaptive Fuzzy Control. IEEE Transaction on Industrial Applications, 35, 461-468. http://dx.doi.org/10.1109/28.753642

[9] Sahoo, S.K., Dasgupta, S., Panda, S.K. and Xu, J.-X. (2012) A Lyapunov Function Based Robust Direct Torque Controller for Switched Reluctance Motor Drive Systems. IEEE Transaction on Power Electronics, 27, 555-564. http://dx.doi.org/10.1109/TPEL.2011.2132740

[10] Shaked, N.T. and Rabinovici, R. (2005) New Procedure for Minimizing the Torque Ripple in Switched Reluctance Motor by Optimizing the Phase Current Profile. IEEE Transaction on Magnetics, 41, 1184-1192. http://dx.doi.org/10.1109/TMAG.2004.843311

[11] Kioskeridis, I. and Mademlis, C. (2005) Maximum Efficiency in Single Pulse Controlled Switched Reluctance Motor Drives. IEEE Transaction on Energy Conversion, 20, 809-817. http://dx.doi.org/10.1109/TEC.2005.853738

[12] Lin, Z.Y., Reay, D.S., Williams, B.W. and He, X.N. (2006) Torque Ripple Reduction Scheme Using B-Spline Neural 
Network. IEEE Transaction on Industrial Applications, 42, 1445-1453. http://dx.doi.org/10.1109/TIA.2006.882671

[13] Krishnan, R., Park, S.Y. and Ha, K.S. (2005) Theory and Operation of a Four Quadrant Switched Reluctance Motor Drive with a Single Controllable Switch-The Lowest Cost Brushless Motor Drive. IEEE Transaction on Industrial Applications, 41, 1047-1055. http://dx.doi.org/10.1109/TIA.2005.851019

[14] Kim, J. and Krishnan, R. (2009) Novel Two Switch Based Switched Reluctance Motor Drive for Low Cost High Volume Application. IEEE Transaction on Industrial Applications, 45, 1241-1248. http://dx.doi.org/10.1109/TIA.2009.2023568

[15] Liang, J., Xu, G., Lee, D.-H. and Ahn, J.W. (2010) Analysis of Passive Boost Power Converter for Three Phase Drive. IEEE Transaction on Industrial Electronics, 57, 2961-2971. http://dx.doi.org/10.1109/TIE.2010.2040558

[16] Dahmane, A., Meebody, F. and Sargos, F.-M. (2001) A Novel Boost Capacitor Circuit to Enhance the Performance of the Switched Reluctance Motor. IEEE 32nd Annual Power Electronics Specialists Conference, Vancouver, 17-21 June 2001, 844-849. http://dx.doi.org/10.1109/pesc.2001.954225

[17] Chan, S. and Bolton, H.R. (1993) Performance Enhancement of Single-Phase Switched-Reluctance Motor by DC Link Voltage Boosting. IEE Proceedings B-Electric Power Applications, 2, 316-322. http://dx.doi.org/10.1049/ip-b.1993.0039

[18] Hwu, K.I. and Liaw, C.M. (2000) DC-Link Voltage Boosting and Switching Control for Switched Reluctance Motor Drives. IEE Proceedings_Electric Power Applications, 147, 337-344. http://dx.doi.org/10.1049/ip-epa:20000540

[19] Lewis, J.D., Bolton, H.R. and Phillips, N.W. (1995) Performance Enhancement of Single and Two Phase SR Drives Using a Capacitor Boost Circuit. Proc. Eur. Power Electron. Appl. Conf., 3, 229-232.

[20] Dessouky, G., Williams, B.W. and Fletcher, J.E. (1998) A Novel Power Converter with Voltage Boosting Capacitors for a Four-Phase SRM Drive. IEEE Transactions on Industrial Electronics, 45, 815-823. http://dx.doi.org/10.1109/41.720339

[21] Muthulakshmi, S. and Dhanasekaran, R. (2014) Performance Analysis of Current Controlled Three Phase Switched Reluctance Motor. International Journal on Recent Trends in Engineering and Technology, 10.

[22] Hu, Y.H., Gan, C., Cao, W.P., Li, C.S. and Finney, S.J. (2015) Split Converter Fed SRM Drive for Flexible Charging in HV/HEV Applications. IEEE Transactions on Industrial Electronics, 62, 6085-6095. http://dx.doi.org/10.1109/TIE.2015.2426142

[23] Cai, W. and Yi, F. (2016) An Integrated Multiport Power Converter with Small Capacitance Requirement for Switched Reluctance Motor Drive. IEEE Transactions on Power Electronics, 31, 3016-3026. http://dx.doi.org/10.1109/TPEL.2015.2442924 